\title{
SIMULATION OF A CENTRALIZED MAIL DISTRIBUTION CENTER
}

\author{
Gustavo A. Diaz \\ Betsi M. Harris \\ Operations Planning and Performance Engineering \\ Southern Regional Operations Center \\ American Express TRS Company \\ 777 American Expressway LS3 \\ Ft. Lauderdale, FL 33337
}

\begin{abstract}
While the utility of simulation in the service industry has always been a topic of debate, there has been a lack of concrete examples demonstrating the value of simulation in a traditional office environment. This paper supports the view that simulation is an extremely useful decision making tool for the operations manager in the service industry through describing an application at American Express Southern Regional Operations Center (SROC) in Ft. Lauderdale, Florida. SROC provides customer and credit services to American Express cardholders with 3,500 employees operating twenty-four hours a day, 365 days per year.
\end{abstract}

The purpose of this paper is to discuss the evaluation of different alternatives to implement a Centralized Mail Distribution Center that receives, processes and forwards mail correspondence from American Express Cardholders to the different industryspecialized Regional Operations Centers (ROCs).

\section{BACKGROUND}

Prior to 1989 there were five major operating centers similar to SROC servicing the Cardmembers (CMs) by product assignment, e.g., a Gold CM was serviced out of Ft. Lauderdale, a Personal (green) CM was serviced out of the Phoenix, New York or North Carolina Operating Centers. A comprehensive effort was undertaken in early 1989 to provide enhanced service to American Express merchants through changing the six major Operating Centers from product designation to industry designation. This meant that SROC would now service all CMs with a car rental or lodging inquiry, North Carolina would service retail inquiries, etc. The project was called one point of contact to the Service Establishments (S/Es) or merchants accepting the American Express card. The idea was that a merchant would deal with one operating center for all inquiries rather than six potential contact points depending upon the card product type. However, it was made clear early on in the project that cardmembers would continue to receive the high level of customer service expected of American Express and that the change from product assigned to industry assigned customer servicing would be transparent to the cardmember.

As one can quickly grasp, the logistics under the one point of S/E contact could easily become unmanageable. For example, a Gold CM could send a retail related inquiry to Ft. Lauderdale who initially sets up a "CM case" and electronically routes it to North Carolina for actual working. The number of possible reroutes through the system was sixty-six up from zero prior to the change.

To address the logistic issues a proposal was made for a Centralized Customer Service Clearinghouse to initially receive all $\mathrm{CM}$ correspondence, set up the $\mathrm{CM}$ cases, and electronically route them to the appropriate industry center. This would provide one point of contact (a clearinghouse) to the $\mathrm{CM}$ also allowing one point of contact to the merchant (industry specialized operating centers)

\section{SIMULATION MODEL}

A simulation model was utilized to determine the impact on three variables - unit cost, timeliness and throughput rates - of two potential scenarios:

- Business As Usual Under One-point of S/E Contact: Cardmembers continue to send correspondence to the Product center which sets up the CM case and electronically routes them to the appropriate Industry center. Some small percent of the mail is also rerouted to the centers. Correspondence is also received with the $\mathrm{CM}$ remittance at the remit centers and is forwarded to the operating centers. See Exhibit I for details on the routing.

- Centralized CM Correspondence Clearinghouse: All Cardmembers would be advised to send inquiries to a centralized location. The clearinghouse will receive all CM correspondence, set up the cases, and route the case 
CORRESPONDENCE ANALYSIS UNIT WORKFLOW PROPOSALS

BUSINESS AS USUAL

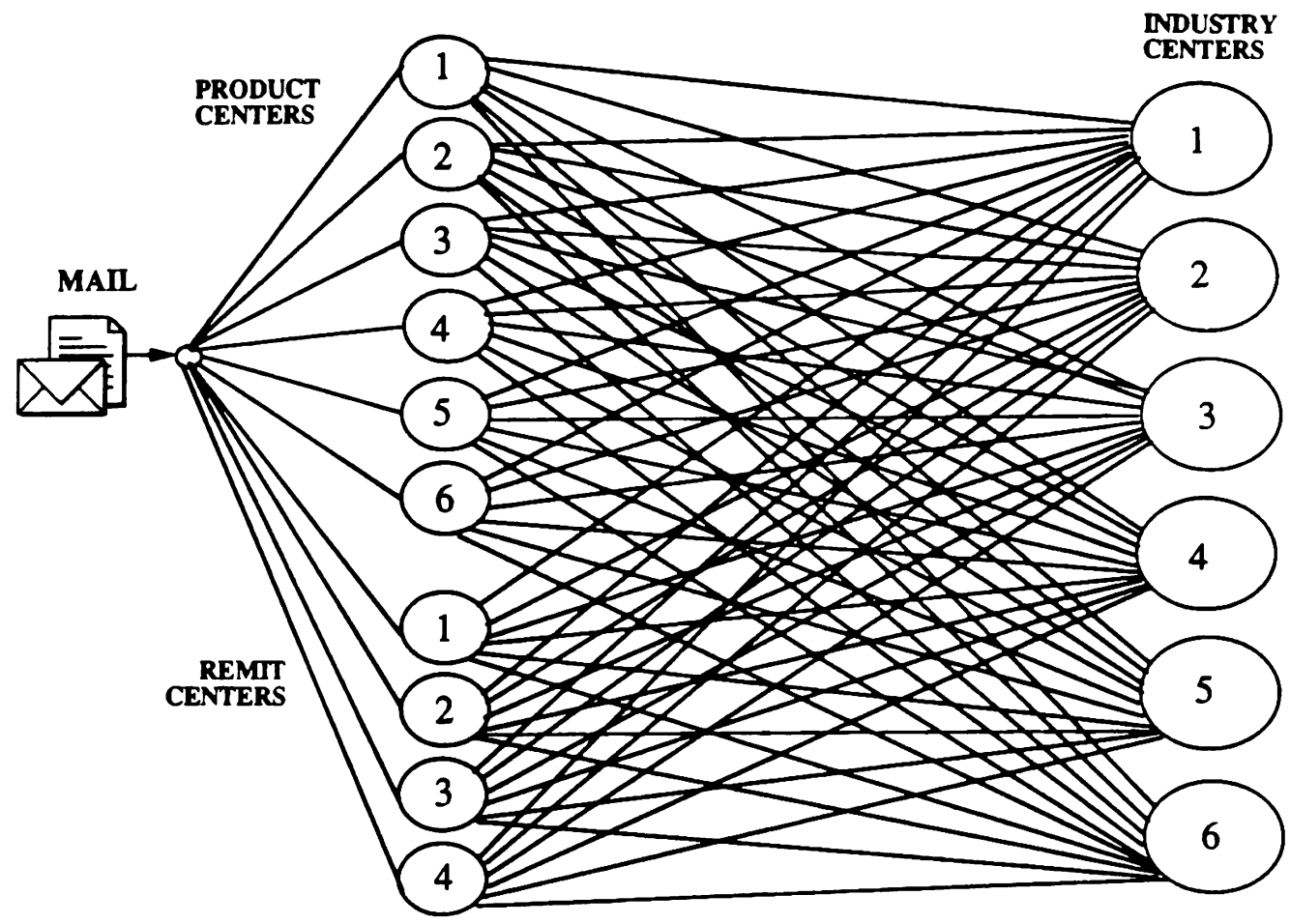

Exhibit 1: Bussines As Usual CM Mailing Network

\section{CORRESPONDENCE ANALYSIS UNIT WORKFLOW PROPOSALS PROPOSED 1 SCENARIO}

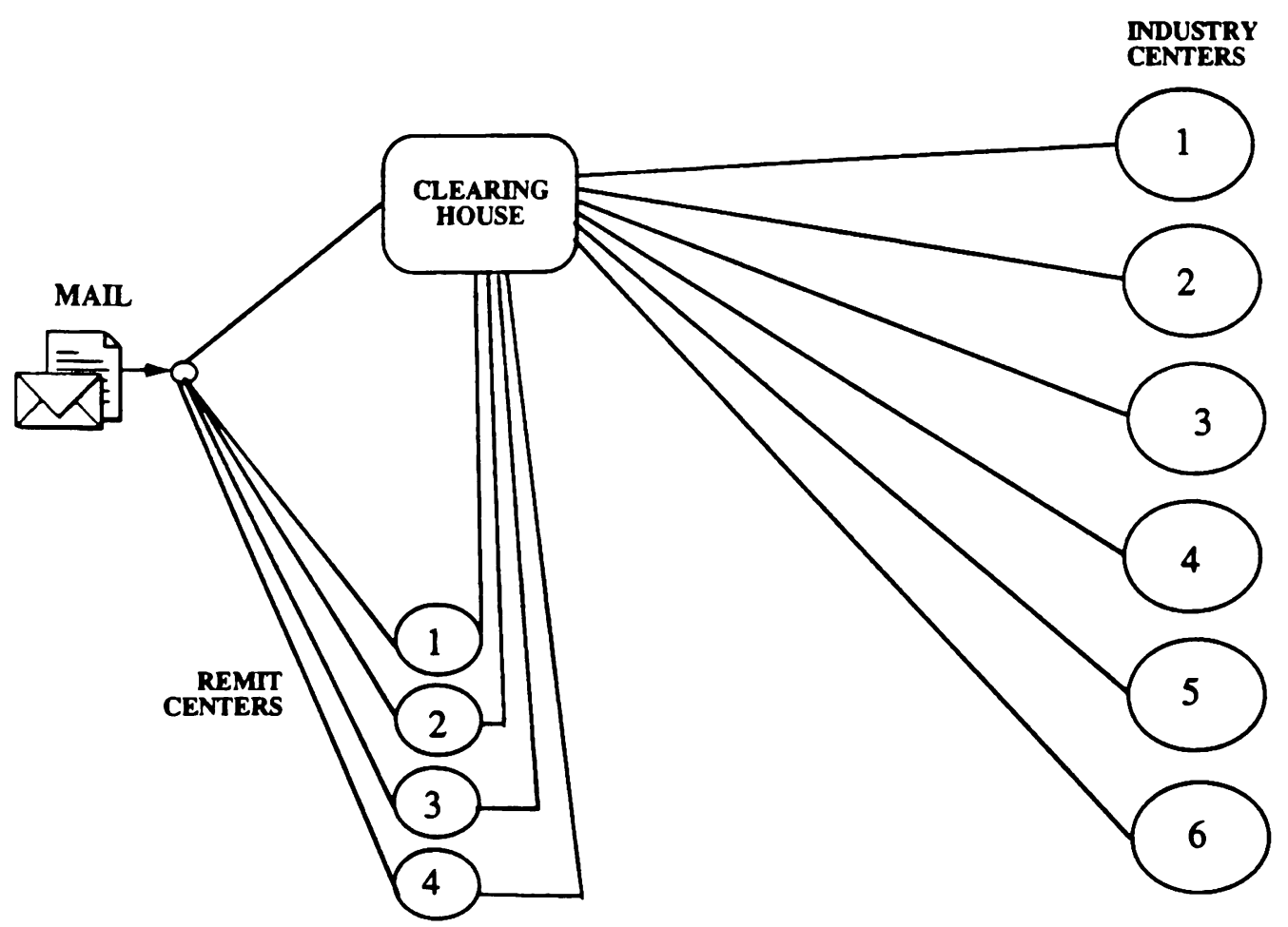

Exhibit 2: Proposed Clearinghouse CM Mailing Network 
correspondence to the appropriate industry center. See Exhibit II for more details.

While the cost impact of the proposed clearinghouse could have been determined through analytical modeling, simulation was necessary to determine the timeliness, staffing and throughput impacts.

Timeliness is an important variable to measure and control since American Express is devoted to high quality customer service and acknowledgment of inquiries should be done within days. American Express also is under federal regulations to respond to CMs inquiries, under the Fair Credit Billing Act. In addition, the resolution time of cardmembers inquiries has a float cost of suspended dollars pending resolution of the inquiry.

Throughput was also an important variable since any scenario examined should guarantee to be able to handle the correspondence levels as cards in force volume grows. Quantifying throughput also helped in determining staffing levels at the different industry centers and the clearinghouse.

\section{MODEL DEVELOPMENT}

The modeling approach was divided in two phases:

- Phase I: A detailed microdescription of two alternatives of handling incoming CM correspondence was modeled. The first approach is a three-step process where mail is received, opened and passed on to a scanner unit where a high level sort is performed. Some types of correspondence is completed at this stage, such as correspondence related to previous inquiries, magazine cancellations and address changes. The remaining pieces go to an analyst unit where cases are set-up and electronically forwarded to the corresponding Customer Service units.

The second approach is a two-step process where mail is received, opened and batched. This "raw" mail is passed onto the analyst unit that works the pieces.

- Phase II: A computer model description of the routing network for business as usual and the clearinghouse scenarios, was developed. The three-step process was assumed under business as usual and the two-step mail processing for the clearinghouse, operating and remit centers under the one-point of contact to the $\mathrm{S} / \mathrm{E}$ project.

Data was collected on monthly historical volume rates, staffing and forecasted inquiries by industry type under business as usual. Estimates for the same variables under S/E Re-engineering were also determined. The CM correspondence flow was charted under each scenario and coded using Systems Modeling's SIMAN / CINEMA simulation / animation software.

This data was used as input to four simulation models. The results were:

- Average time in system by industry type and product center.

- Labor and routing unit costs for clearinghouse, operating and remit centers.

- Staff requirements / productivity for the clearinghouse, operating and remit centers.

The simulation model consisted of approximately two-thousand lines of code. The flow of one-hundred pieces of mail per transaction was detailed in both the clearinghouse and product centers with units processed per hour for six different transaction types incorporated into the model. Each center has experienced, according to historicals, a different level of efficiency and unit cost, which was also captured in the computer models.

Two animations were also developed to help management to visually asses the results achieved through simulation. Animation helps the simulationist both in the debugging as well as a strong presentation tool to non-simulationists.

\section{RESULTS}

The micro-simulation showed that the two-step process yields a $20 \%$ increase in productivity, measured as hourly pieces processed, compared to the three-step process. In addition, an improvement of about $25 \%$ in aging of the pieces was shown under the two-step process. Input rates and staffing levels remained constant during the runs. As a result of the micro-simulation, the two-step process was assumed for the clearinghouse proposal.

The results of the simulation indicated that implementation of the clearinghouse proposal would result in annual saving of $\$ 1.0$ million, while timeliness would improve in $27 \%$. The savings result from labor and routing efficiencies. The proposal was accepted by Senior Management and at the time of this writing, location of the clearinghouse and staffing arrangements were in process.

\section{REFERENCES}

Banks, J., Carson, J.S. 1984. Discrete-event System Simulation, First Edition. New Jersey: Prentice-Hall, Inc. 
Hillier, F.S., Lieberman, G.J. 1980. Introduction to Operations Research. Third Edition. San Francisco: Holden-Day, Inc.

Law, A.M., Kelton, W.D. 1982. Simulation Modeling and Analysis, First Edition. New York: McGraw-Hill, Inc.

Pegden, C.D., Shannon, R.E., Sadowski, R.P. 1990. Introduction to Simulation Using SIMAN, First Edition. New York: McGraw-Hill, Inc.

\section{AUTHOR BIOGRAPHIES}

GUSTAVO A. DIAZ is Senior Operations Research Analyst in the Performance Engineering Department at American Express Southern Regional Operations Center. He received a M.A. in mathematics and a M.E. in industrial engineering from The Pennsylvania State University and is a Ph.D. student at Florida International University. His interest is simulation applications in the service industry. He is a member of ORSA/TIMS and Vicepresident of Ft. Lauderdale Chapter of IIE.

BETSI M. HARRIS is Manager of the Performance Engineering Department at American Express Southern Regional Operations Center. She received a B.Sc. in industrial engineering from Georgia Institute of Technology, a M.B.A. from the University of Connecticut and is a Ph.D. student at Florida Atlantic University. Her interest is simulation applications and Total Quality Management. She is President of the Ft. Lauderdale Chapter of IIE. 